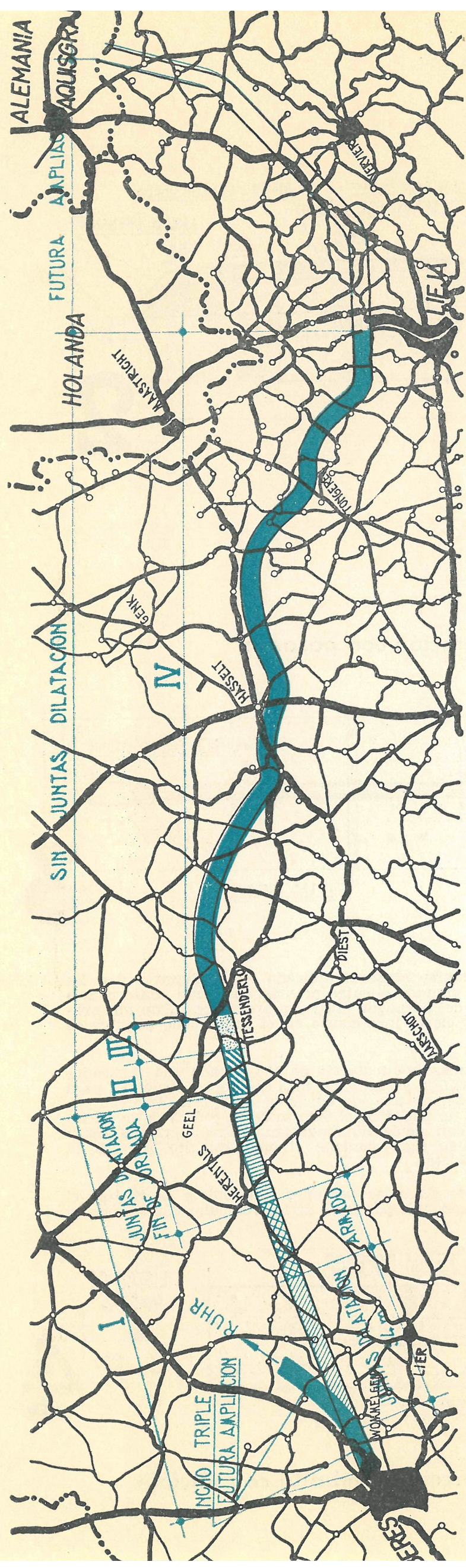

\section{firme de hormigón \\ en la \\ autopista de Amberes a Lieja \\ SANDRO}

La autopista "Rey Balduíno" comunica la ciudad portuaria de Amberes (el tercer puerto europeo, después de Rotterdam y Londres) con el centro industrial de Lieja, a orillas del Mosa, constituyendo, por lo tanto, una arteria vital para la nación belga. Está prevista su extensión hasta Aquisgrán, y el enlace directo con el sistema de autopistas alemanas de la zona del Ruhr con lo que llegará a ser una vía de penetración comercial desde el mar hasta dicha importantísima zona, servida ya por el tráfico mavial del Rhin.

La longitud total de la autopista será de $111 \mathrm{~km}$, repartidos como sigue:

\begin{tabular}{|c|c|c|}
\hline \multirow{4}{*}{\multicolumn{2}{|c|}{$\begin{array}{l}\text { Tramo I.-Amberes (Wommelgen)-Geel } \\
\text { Tramo II.-Geel-Tessenderlo } \\
\text { Tramo III.-Tessenderlo-Paal } \\
\text { Tramo IV.-Paal-Lieja }\end{array}$}} & $34 \mathrm{~km}$ \\
\hline & & $12 \mathrm{~km}$ \\
\hline & & \\
\hline & & $57 \mathrm{~km}$ \\
\hline & 100 & \\
\hline
\end{tabular}

\title{
tramo
}

Estos tramos se han ido construyendo sucesivamente a partir de Amberes; su estado actual es, en el momento de mi visita (agosto 1960), el siguiente:

El tramo I, Wommelgen-Geel, está abierto al tráfico.

El tramo II, Geel-Tessenderlo, está en fase muy adelantada de ejecución, previéndose su apertura al tráfico en un plazo de tres meses.

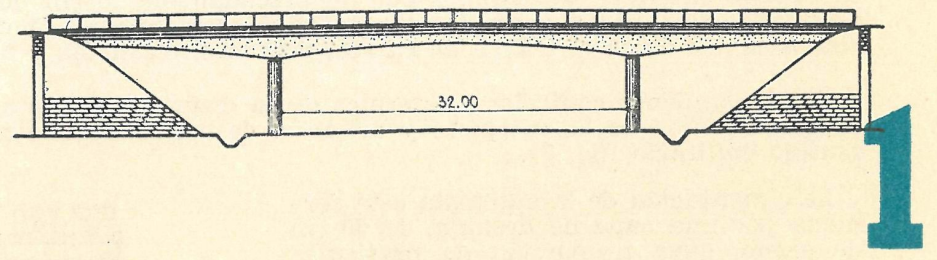

El tramo III Tessenderlo-Paal, está todavía en periodo de explanación, aunque los puentes y obras de fábrica están ya terminados.

El tramo IV, Paal-Lieja, aún no ha sido empezado.

Naturalmente, ofrece el máximo interés para el técnico el tramo II, en vías de ejecución, cuyo coste junto con el tramo III, supone un presupuesto de 275 millones de francos belgas, o sea, 16,5 millones de pesetas por $\mathrm{km}$, de los cuales, aproximadamente, 3,6 millones corresponden al firme de hormigón, que viene a resultar en un precio de unas 240 pesetas por metro cuadrado. 


\section{sección transversal}

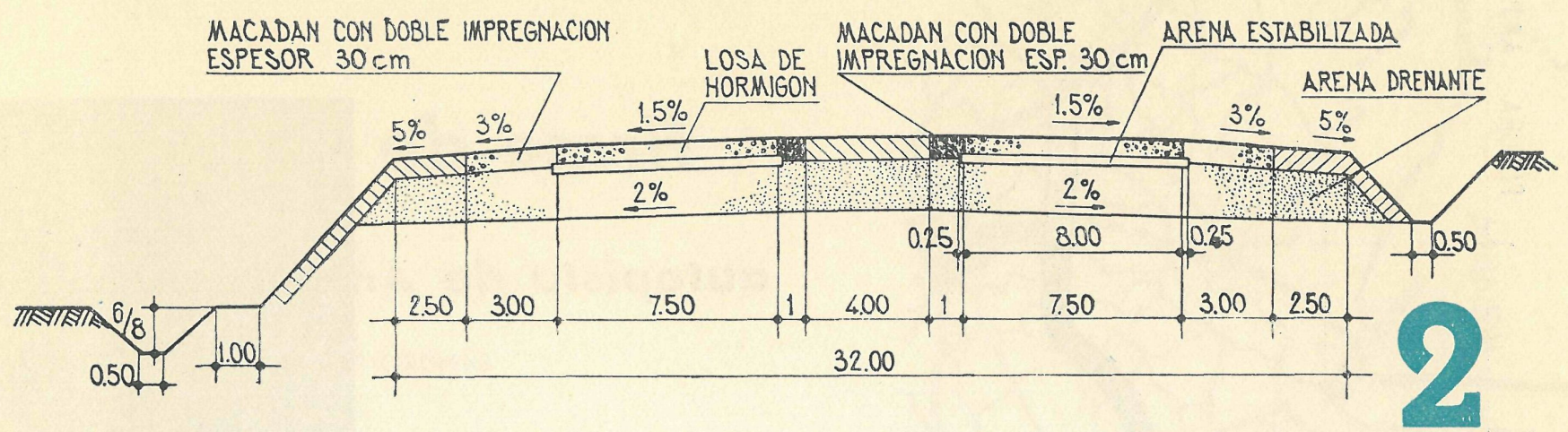

\section{junta de dilatación con pasador}

A fin de evitar cruces a nivel, ha sido preciso construir puentes para las carreteras secundarias que cortan a la autopista. su número es muy elevado (como media, un puente por kilómetro).

En el tramo I hay 13 pasos inferiores y 21 superiores.

En los tramos II y III hay 20 pasos superiores.

Todos estos pasos son de hormigón ar-

mado e incluso pretensado, a elección del contratista, que sólo debe ajustarse al perfil indicado en la figura 1 y a los trenes de cargas vigentes, habiéndose encontrado ciertas dificultades en algunos puentes pretensados como consecuencia de la delgadez de las vigas proyectadas, lo cual dificultaba la penetración del hormigón entre las armaduras. Este inconveniente se ha subsanado en puentes proyectados con posterioridad y causó cierto incremento en el número de puentes de hormigón armado.

La sección transversal tipo, indicada en la figura 2, consta de dos calzadas de circulación de 7,50 m cada una, separadas por un andén central de $4 \mathrm{~m}$; este andén llega a tener un ancho de $11,50 \mathrm{~m}$ en los $6 \mathrm{~km}$ más cercanos a Amberes, para que cuando se construya el ramal en dirección al Ruhr se pueda disponer de una vía adicional de $3,75 \mathrm{~m}$ de ancho en cada sentido. Además, cada calzada está bordeada por márgenes de $1 \mathrm{~m}$ de ancho en el lado interior, y de $3 \mathrm{~m}$ de ancho en el lado exterior, constituídos por un macadam de $30 \mathrm{~cm}$ de espesor con doble impregnación. Estos márgenes están destinados tan sólo a vehículos averiados o accidentados. Queda prohibido rigurosamente el aparcamiento en toda la autopista, así como el tráfico de carros, peatones, bicicletas y aun motocicletas.

En los andenes centrales y laterales se ha dispuesto un seco de plantas de hojas perennes, con objeto de realzar el aspecto estético de la autopista y evitar el deslumbramiento nocturno producido por faros de los vehículos que ruedan en sentido contrario (fig. 7).

La cimentación de la autopista está formada por una capa de drenaje, de $60 \mathrm{~cm}$ de arena, cuya proporción de partículas inferiores a $20 \mu$ es menor de $5 \%$. Esta capa se compacta hasta el $100 \%$ de la densidad óptima (Proctor modificado).

Los taludes laterales son de arena, con un porcentaje inferior al $20 \%$ de partículas menores de $20 \mu$, compactada hasta el $95 \%$ de la densidad óptima.
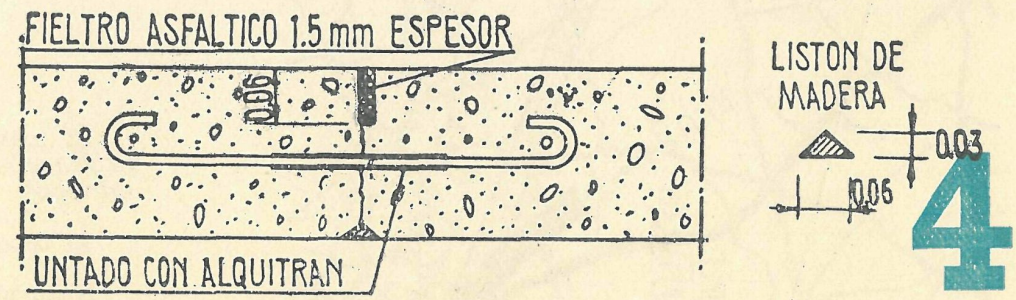

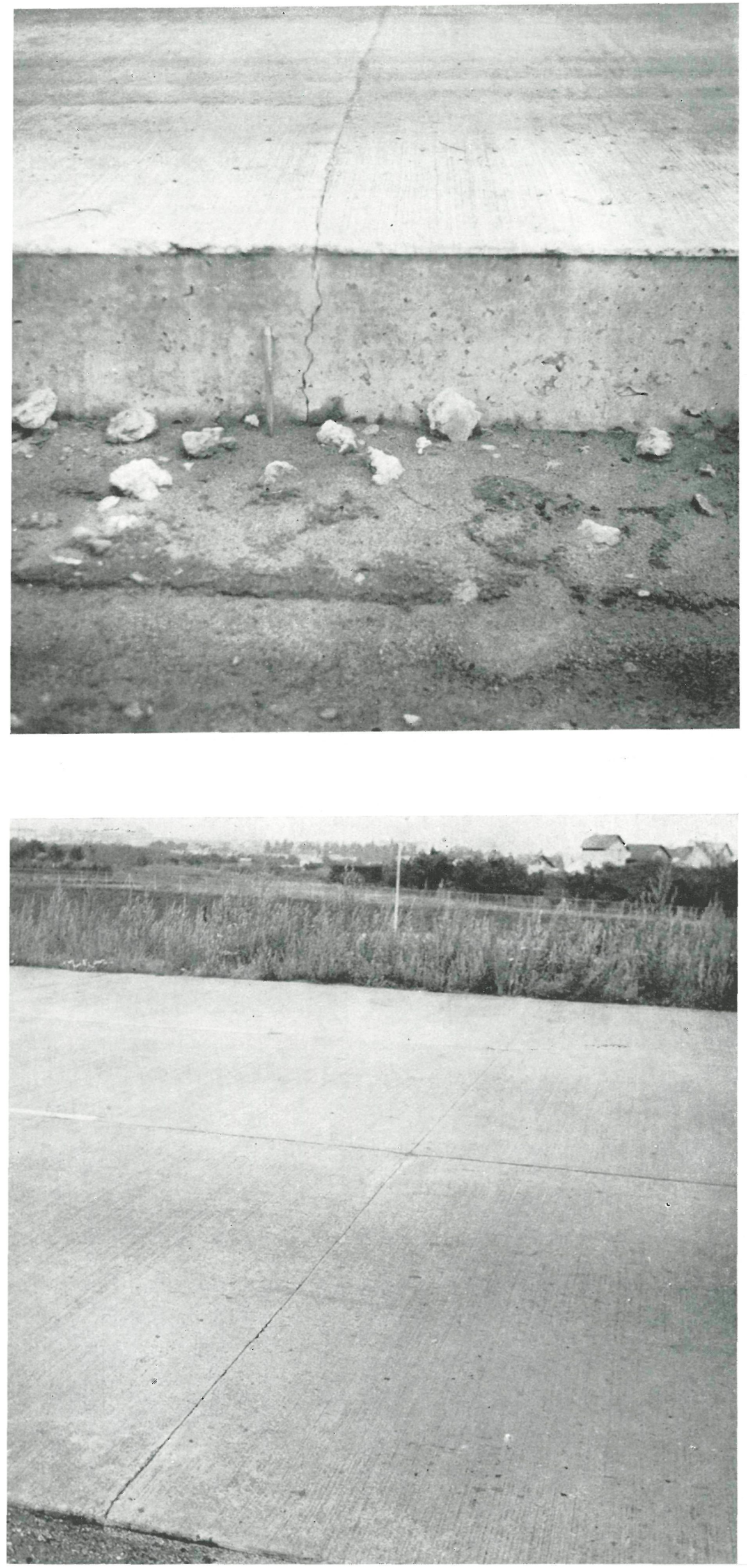

Sobre la sub-base de drenaje se dispone una base de $15 \mathrm{~cm}$ de tierra estabilizada con brea, "cut-back" o cemento, según los lugares y los contratistas.

Inmediatamente encima se hormigona la losa del firme sobre un papel impermeable, con un espesor de $23 \mathrm{~cm}$ en toda la calzada, salvo en un tramo armado entre los $\mathrm{km} 13$ y 20 a partir de Amberes, en que el espesor baja a 20 centímetros.

\section{materiales}

El hormigón utilizado tiene las características siguientes:

Composición granulométrica: Hay dos tipos, uno de granulometría continua y otro de granulometría discontinua y otro de granulometria discontinua, utilizados indistintamente, sedosificaciones son empleadas profusamente por la técnica belga de construcción de carreteras:

Granulometría Granulometría

Cemento continua

Arena de río

$$
400 \mathrm{~kg} / \mathrm{m}^{3} \quad 350 \mathrm{~kg} / \mathrm{m}^{3}
$$

$$
270 \text { litros } / \mathrm{m}^{3} \quad 400 \mathrm{~kg} / \mathrm{m}^{3}
$$

Gravilla 2 a $8 \mathrm{~mm}$

270 litros $/ \mathrm{m}^{3}$

Gravilla 8 a 16 mm

Gravilla 8 a $22 \mathrm{~mm}$

270 litros $/ \mathrm{m}^{3}$

Grava 22 a $40 \mathrm{~mm}$

540 litros $/ \mathrm{m}^{3}$

Grava 40 a $63 \mathrm{~mm}$

Se emplean cementos Portland de alta resistencia o cementos de alto horno, indistintamente, de fabricación nacional belga.

Llama la atención la reducida cantidad de agua en el hormigón utilizado, que oscila entre 0,35 y 0,40 del peso del cemento. Sin embargo, como se verá a continuación, hormigones tan secos no son en absoluto difíciles de poner en obra. 

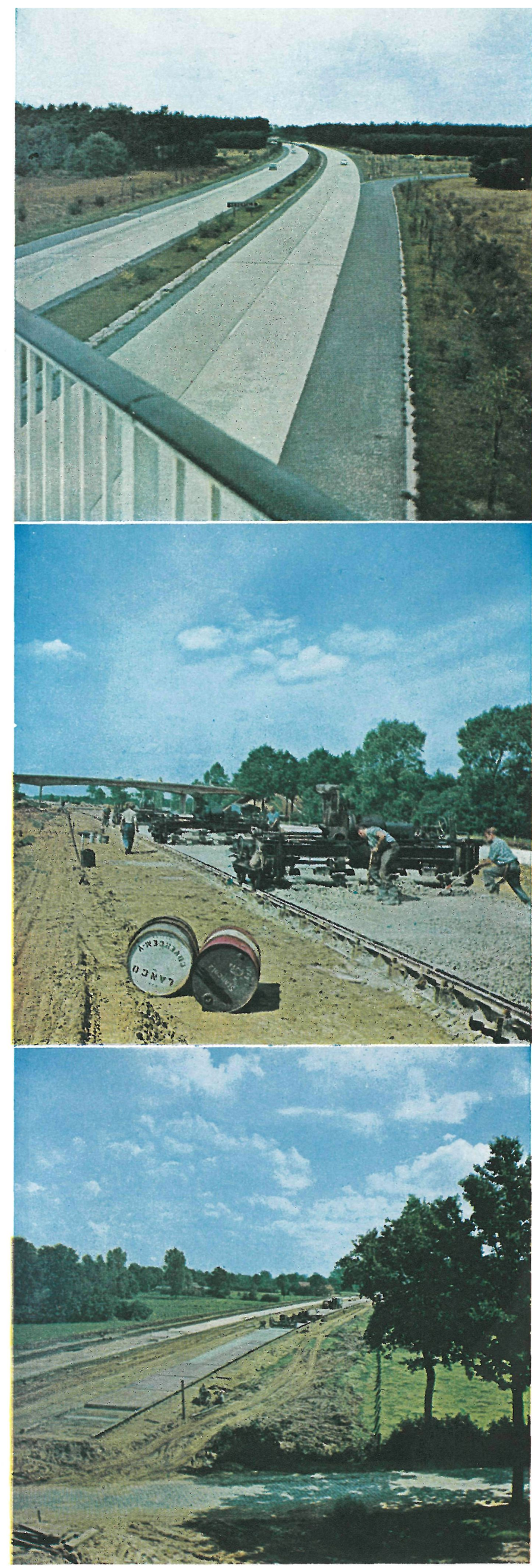

En el tramo armado de $7 \mathrm{~km}$, se dispone una armadura formada por una malla electrosoldada de $\varnothing 12$ longitudinales espaciados a $15 \mathrm{~cm}$ y de $\varnothing 6$ transversales cada $40 \mathrm{~cm}$. El límite elástico del acero es de $6.000 \mathrm{~kg} / \mathrm{cm}^{2}$. Esta armadura está a la mitad del canto de la losa, y se ha dispuesto en un tramo en que se han suprimido las juntas de retracción; su comportamiento ha sido excelente, como lo demuestra el que de 280 losas, el 92,5\% no presentan fisura alguna; 18 losas tienen 1 sola fisura, y otras 3 , respectivamente, 3, 6 y 13 fisuras. El caso de esta última es excepcional: presenta a $30 \mathrm{~cm}$ de la junta de dilatación una ancha grieta, atribuible a una colocación defectuosa de los pasadores, que impediría su movimiento.

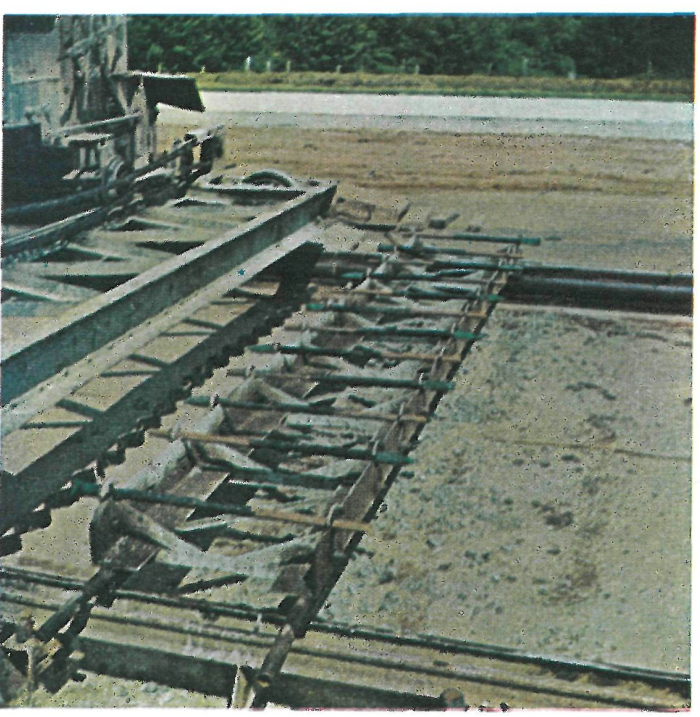

\section{juntas}

En esta autopista existen dos tipos de juntas transversales:

a) Juntas de dilatación (discontinuas).

b) Juntas de retracción-combado (continuas).

Las primeras llevan siempre pasadores, y son del tipo representado en la figura 3. Los pasadores, alquitranados en su mitad, llevan en el extremo correspondiente a dicha mitad una caperuza de plástico obtenida cortando un trozo de manguera, y llena de serrín, para permitir el juego de la junta. 
Estas caperuzas van dispuestas alternativamente a un lado y a otro de la junta (fig. 10). El material de relleno de la junta es un fieltro especial cuya altura es algo menor que el canto, y el resto se sella con un producto bituminoso, técnica muy conocida.

Las juntas de retracción-combado son del tipo llamado "holandés" Pueden llevar pasadores, o bien sustituir éstos con un anclaje (como se describe en la figura 4) cuya parte central se alquitrana para que deslice y evite la fisuración de los alrededores de la junta, repartiendo el alargamiento del redondo. Aunque llevan el nombre de juntas, en realidad no lo son. Son más bien secciones débiles en las que se localizan las fisuras debidas a retracción y combado higrotérmico; para ello llevan dispuestas dos entallas: la superior, de unos $6 \mathrm{~cm}$ de profundidad, sellada por un doble fieltro asfáltico de $1,5 \mathrm{~mm}$ de espesor; la inferior consiste en un "cuerpo extraño", ya sea listón de madera como en la figura 4, o mejor un recorte de placa ondulada de fibrocemento de unos 3 ó $4 \mathrm{~cm}$ de altura (fig. 14), pero en ambos casos van alquitranadas para que el hormigón no se adhiera y rompa limpiamente (fig. 5). La ejecución de estas juntas se describe más adelante con todo detalle.

La enorme ventaja de la junta de retracción-combado de tipo holandés es que no representa ninguna discontinuidad en el firme (siendo su ancho total de 2 ó $3 \mathrm{~mm}$ ) y que garantiza la impermeabilidad sin necesidad de conservación ninguna, pues no emplea productos bituminosos de sellado.

Las juntas de retracción-combado se espacían sucesivamente cada 7, 8, 9 y $10 \mathrm{~m}$, con objeto de evitar cualquier efecto de resonancia en los vehículos que transitan. En el tramo armado han sido suprimidas, y llevan pasadores en el tramo en que no hay juntas discontinuas o de dilatación.
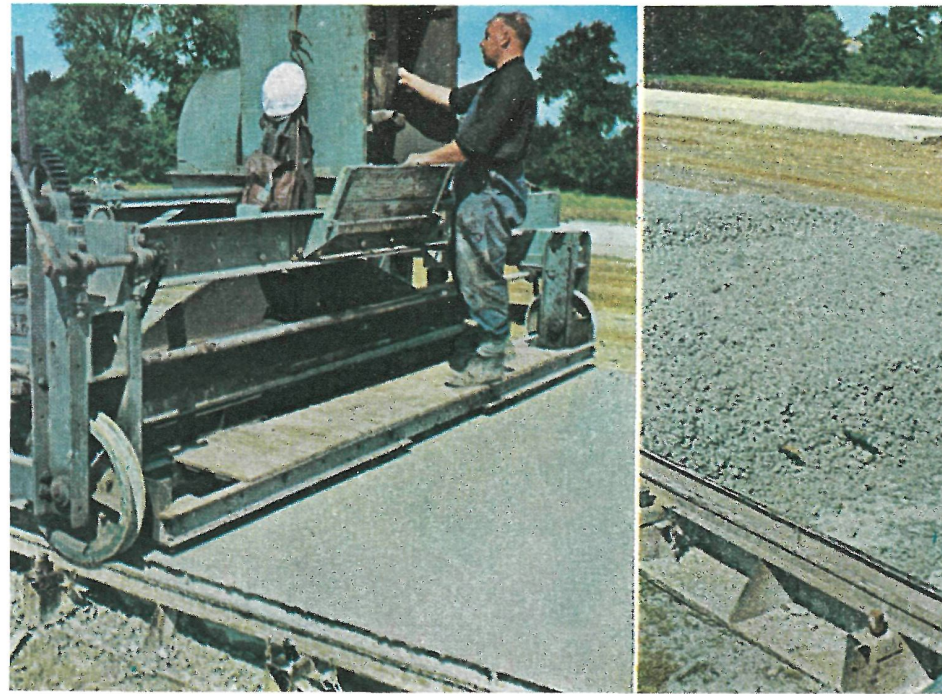

11
Estas últimas han ido evolucionando a medida que se construye la autopista Al principio, cerca de Amberes, se disponían cada $34 \mathrm{~m}$. A continuación, en el tramo armado, se espacían a $100 \mathrm{~m}$. Más adelante se suprimen del todo, quedando únicamente las juntas de retracción-combado, y siendo entonces la superficie del firme absolutamente uniforme.

Quedan, por último, las juntas de hormigonado:

Las longitudinales presentan un perfil machihembrado para asegurar la transferencia de cargas de una losa a otra y evitar su desnivelación. Se hormigona sobre ellas tomando sólo la precaución de barnizar con alquitrán el paramento de la losa contigua para que no se adhiera el hormigón fresco. Y se forma luego, mediante aserrado del hormigón endurecido, una ranura en la parte superior que se sella con un producto bituminoso.
12
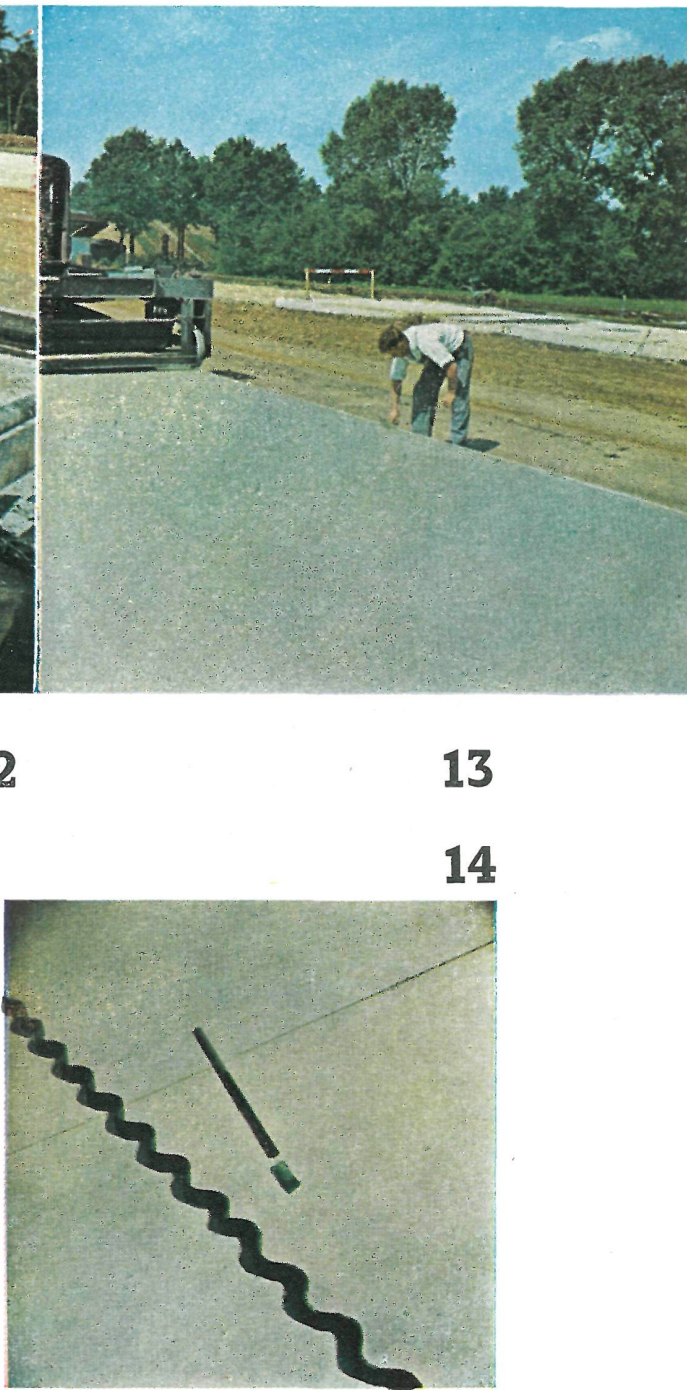
Las transversales también han seguido una marcha paralela a las de dilatación. Al principio (primer tramo) se procuraba terminar la jornada en una junta, y se disponía allí una junta de dilatación. En los últimos tramos se acaba la jornada a mitad de una losa y se prosigue al día siguiente sin especiales precauciones.

Los últimos tramos de la autopista presentan, por tanto, sólo juntas "ciegas" o discontinuas de 2 ó $3 \mathrm{~mm}$ de ancho, prácticamente inapreciables al tráfico (fig. 6).

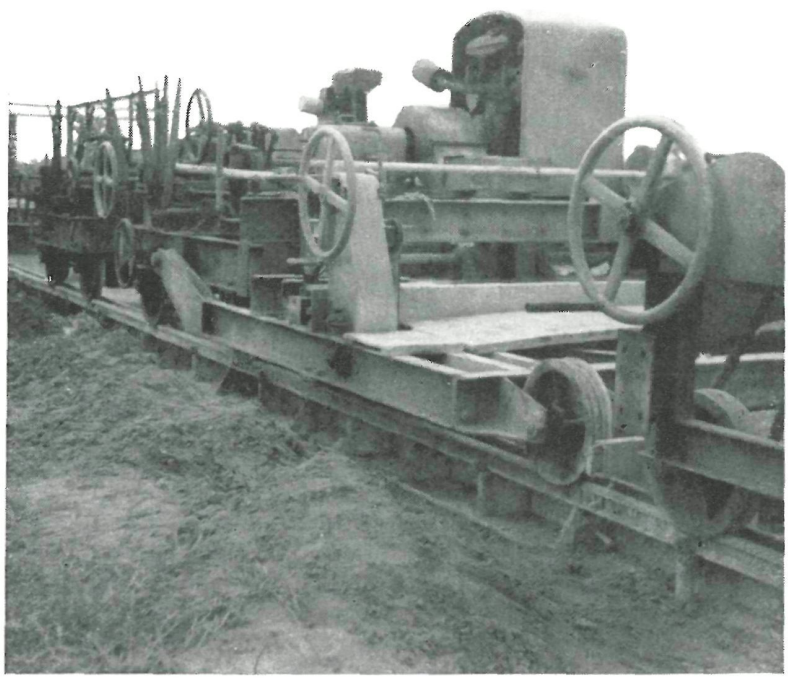

\section{ejecución}

Los trabajos de ejecución del firme de hormigón se contratan por tramos de unos $3,5 \mathrm{~km}$. Se procede por bandas sucesivas de un ancho igual a la mitad del total de cada calzada; o sea: 3,75 metros.

La maquinaria utilizada es de fabricación belga (S. G. M. E.), y cada tajo se dispone de la forma que se describe a continuación (fig, 15).

Gracias a la proximidad del Canal Alberto, el aprovisionamiento de cemento se realiza por vía fluvial, hallándose la central de hormigonado a orillas del Canal.

El hormigón recién amasado se transporta a la obra en camiones de 5 toneladas, con un recorrido máximo de 5 minutos para evitar segregaciones del árido y falsos fraguados.

Los encofrados han sido dispuestos previamente en la posición definitiva, y untados con alquitrán para facilitar el desencofrado. Sobre el fondo de la caja, constituído por la base de tierra estabilizada, generalmente de suelo-cemento, se coloca papel fuerte impermeable (este papel para su más fácil manejo viene en rollos).

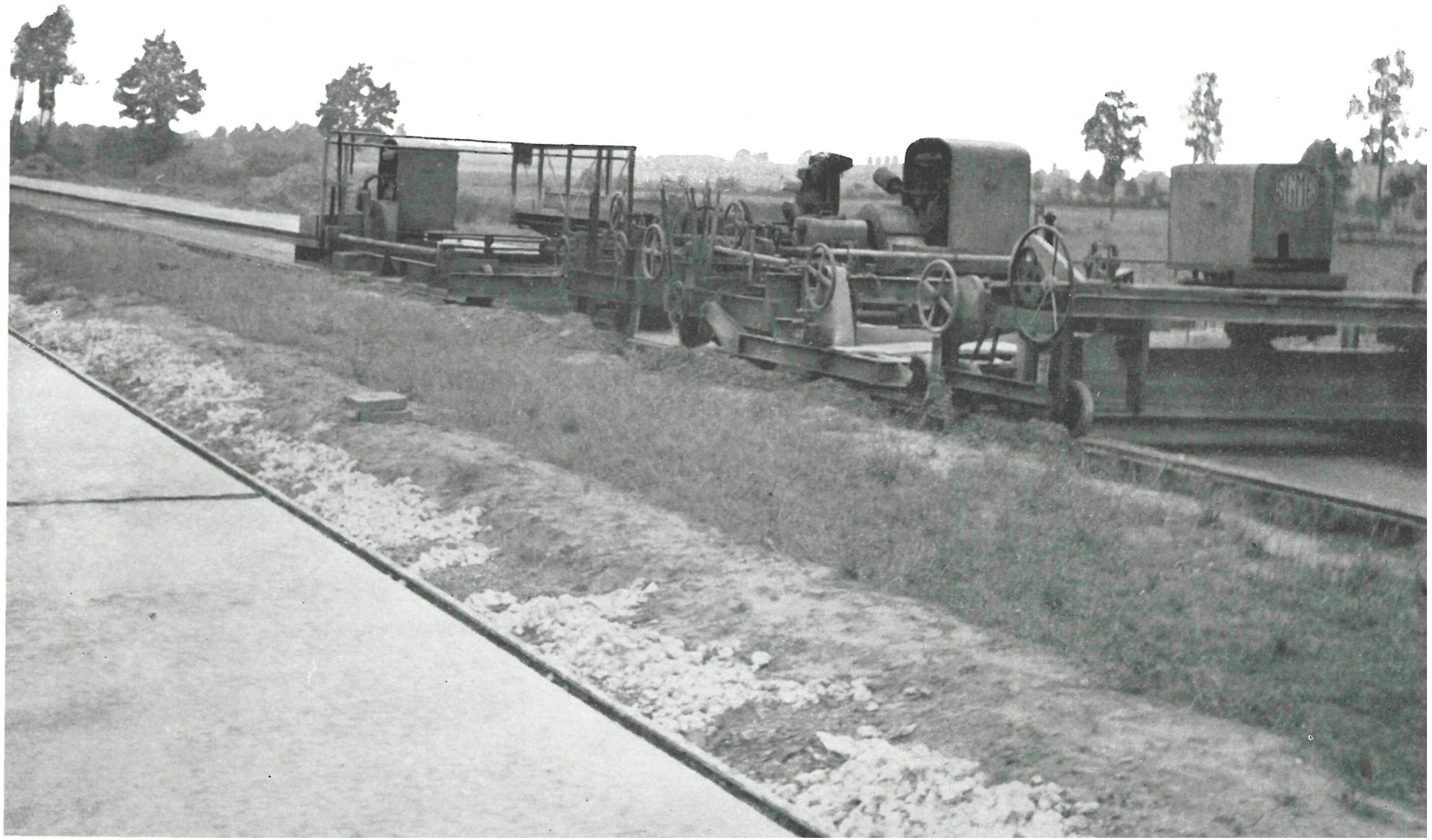




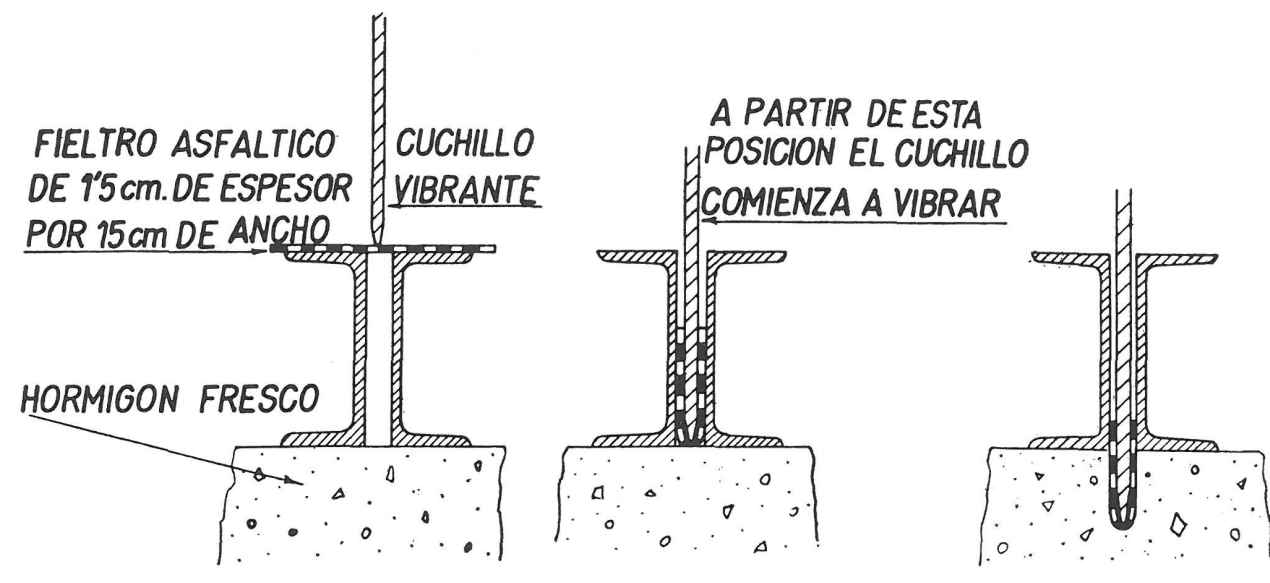

ejecución

de la junta de retracción - combado
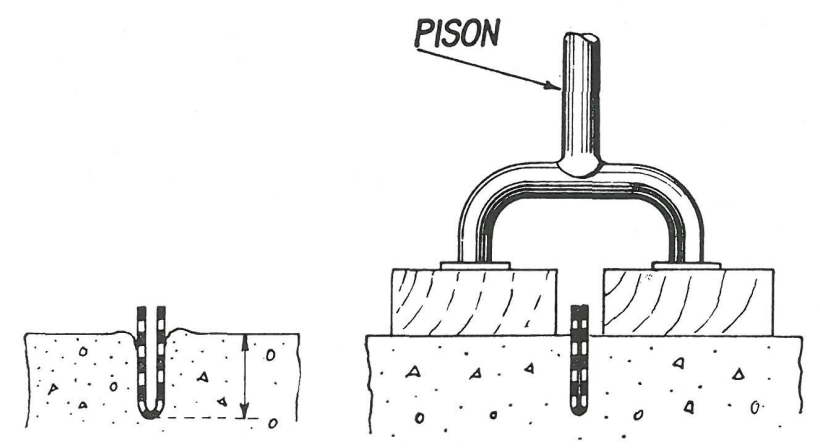

\section{MADERO DE APOYO PARA} SOPORTE DEL FIELTRO
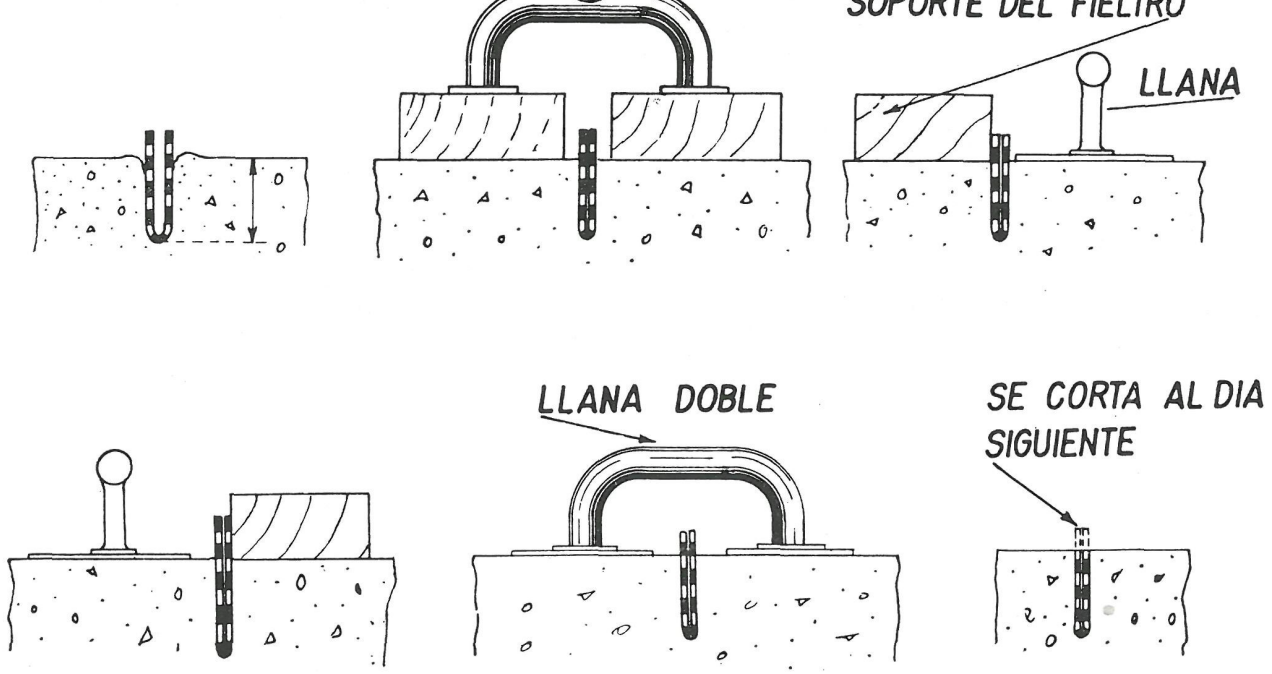

Las juntas se disponen a las distancias preestablecidas. Los pasadores se colocan por medio de una "cuna", la cual asegura su colocación exacta y va apoyada en los encofrados (fig. 10).

Cuando llega el camión que transporta el hormigón, lo vierte en la tolva múltiple de una máquina repartidora, salvo una pequeña parte que deposita al lado de la junta más cercana al frente del tajo.

Dos peones palean el hormigón hasta cubrir la junta y los pasadores, y un tercer peón vibra el conjunto con un vibrador portátil de aguja accionado por un motor de gasolina (fig. 8).

Entre tanto, la máquina repartidora, seguida de tres o cuatro peones, va avanzando y dejando el hormigón un poco por encima del nivel del encofrado. Se obtiene así una primera rasante uniforme con ayuda de rastrillos de púa larga, para conseguir un primera rasante uniforme con ayuda de rastrillos de púa larga, para conseguir un previamente hormigonada, se termina de hormigonar hasta enrasar (fig. 12).

La extendedora-vibradora es la máquina fundamental del trabajo. En la parte anterior lleva un árbol con paletas que van "lamiendo" el hormigón y rechazando el sobrante frente a sí, alcanzando una rasante uniforme un poco por encima del encofrado. 


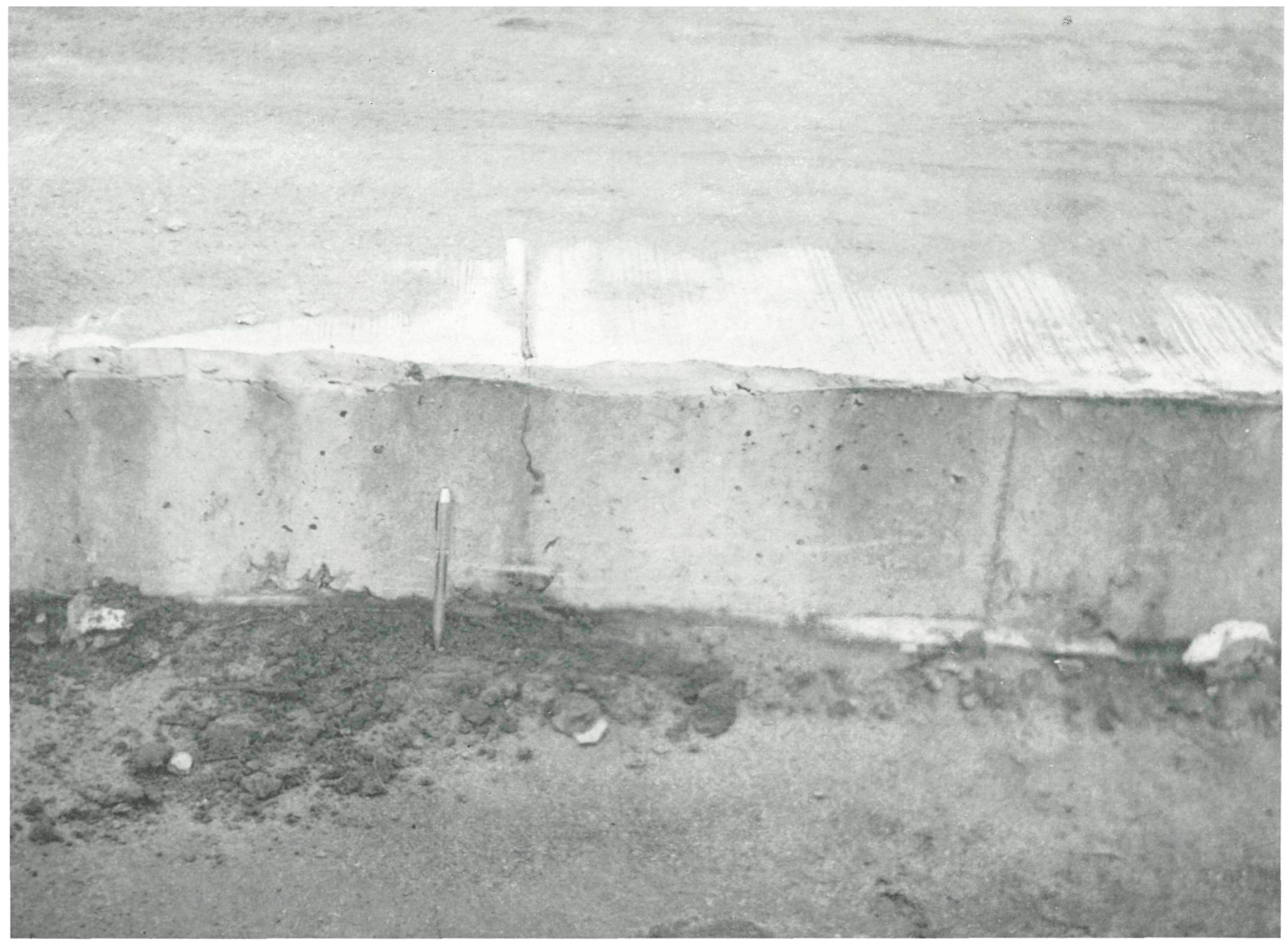

Los antedichos peones atienden a colmatar eventuales huecos. En la parte posterior va una viga vibrante a todo lo ancho, que efectúa la compactación del hormigón y lo deja perfectamente alisado.

Con objeto de evitar que la máquina tenga que dar dos pasadas, se utilizan dos: una a continuación de la otra (fig. 8). La segunda máquina va un poco más baja que la primera sobre los encofrados. A ésta le sigue una maestra alisadora que tiene un movimiento de vaivén transversal y que rectifica definitivamente la rasante, pues está apoyada en un sistema de tiene un movimiento de vaivén transversal y que rectifica definitivamente la rasante, pues está apoyada en un sistema de
cuatro ruedas (fig. 16) por cada lado, que compensan posibles desnivelaciones del encofrado. Un peón con una llana va retocando los márgenes entre las dos extendedoras-vibradoras (fig. 13).

Cierra la marcha el cuchillo de hacer juntas (fig. 11), o cuchillo vibrante. El proceso es como sigue (fig. 17): se dispone una tira de fieltro asfáltico a todo lo ancho de la calzada, apoyada en dos perfiles que lleva la máquina en su parte inferior. Se baja entonces el cuchillo, que penetra entre los perfiles arrastrando la tira doblada hasta reposar sobre la superficie del hormigón fresco. Se pone en acción el vibrador, que comunica su movimiento al cuchillo y lo introduce arrastrando al fieltro doblado hasta una profundidad de $6 \mathrm{~cm}$; entonces se retira el cuchillo dejando el fieltro embebido en el hormigón, pero asomando sus extremos superiores (fig. 18). Se termina la junta a mano, como se indica en la figura, $y$ al día siguiente se corta el exceso de fieltro que asoma, quedando la junta con un ancho total de 2 a $3 \mathrm{~mm}$ (fig. 19).

Al desplazarse el cuchillo de juntas lentamente, un peón, colocado en su pasarela posterior, barre transversalmente el firme con una escoba de alambre para conferirle una rugosidad que aumente la adherencia de las ruedas de los vehículos.

Queda tan sólo el esparcir sobre la superficie del firme un producto de curado (fig. 9), que impide la evaporación del agua del hormigón, y, por tanto, aminora la retracción. Esto se hace por medio de un pulverizador; resulta tan eficaz, que se ha observado que de las juntas de retracción-combado trabajan generalmente una de cada dos o tres, quedando las demás sin abrirse; esto es, sin fisurarse el hormigón en su centro (fig. 19).

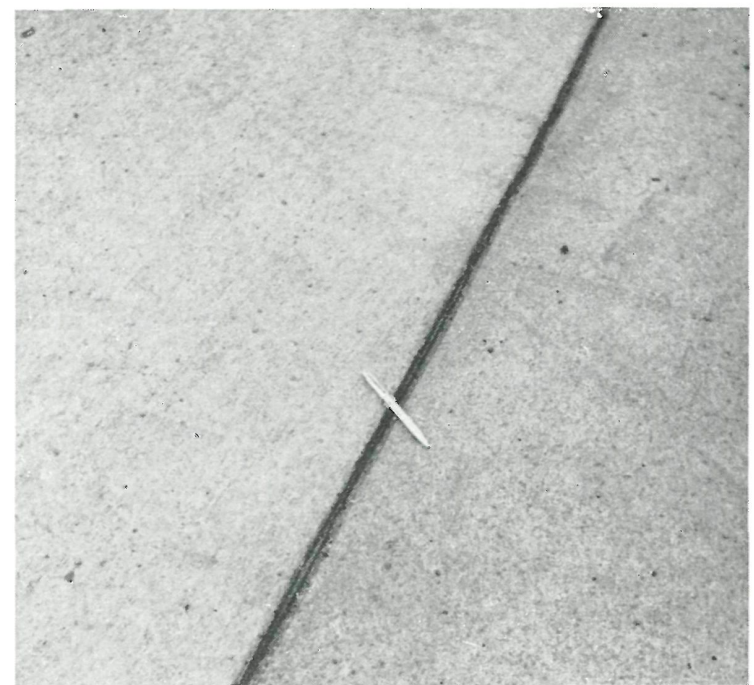

